\title{
Pedagogical and Personal Experiences Motivating Indigenous Students to Pursue Medical Studies
}

\author{
Tanya Chichekian $^{1 *}$, Léa Bragoli-Barzan ${ }^{2}$ and Sonia Rahimi ${ }^{2}$ \\ ${ }^{1}$ Department of Pedagogy, Université de Sherbrooke, Sherbrooke, QC, Canada, ${ }^{2}$ Department of Psychology, Université du \\ Québec À Montréal, Montreal, QC, Canada
}

When it comes to accessibility to healthcare and medical education, inequalities prevail within ethnically diverse populations, especially among Indigenous Peoples. The main objective of this qualitative study was to explore how Indigenous female medical students' motivations played a role in their pursuit of a medical career. We use the Self-Determination theory to frame this study and conduct individual open-ended interviews with four female Indigenous students' regarding their motivational sources for applying to medical school. We provide an illustrative scenario for each identified motivational source through a thematic analysis. Results revealed two main sources of motivations: (Jones et al., Acad Med, 2019, 94 (4), 512-519) pedagogical experiences (i.e., contextual factors at

OPEN ACCESS

Edited by: Ramón Chacón-Cuberos, University of Granada, Spain

Reviewed by:

Azadeh Farrah Osanloo, New Mexico State University, United States

Mariana Pérez Mármol, University of Granada, Spain

*Correspondence:

Tanya Chichekian

tanya.chichekian@usherbrooke.ca

Specialty section:

This article was submitted to Educational Psychology, a section of the journal Frontiers in Education

Received: 03 October 2021 Accepted: 27 December 2021 Published: 14 January 2022

Citation: Chichekian T, Bragoli-Barzan L and Rahimi S (2022) Pedagogical and Personal Experiences Motivating Indigenous Students to Pursue Medical Studies.

Front. Educ. 6:788909. doi: 10.3389/feduc.2021.788909 school, academic interests, and opportunities) and (Sloof et al., Med Educ, 2021, 55 (5), 653) personal experiences (i.e., family support and influence, and future career prospects). Indigenous students' personal experiences were more prevalent and described autonomous forms of motivations, whereas sources of motivation that were pedagogically oriented reflected more controlled forms of motivations. Different types of motivations can be useful, but not sufficient for the tipping point when the time comes for medical school applications. Learning about specialized Indigenous streams for admissions played the most influential role in students' decision-making to pursue medical studies. Promoting the visibility of the Indigenous stream coupled with the identification of different forms of motivation could be informative when outlining evidence-based recommendations with the aim of improving inequalities within the health professions.

Keywords: indigenous, students, medicine, education, motivation

\section{INTRODUCTION}

Increasing diversity in societies and new emerging demographic realities such as super-diversity (Grzymala-Kazlowska and Phillimore, 2018) demonstrate the need for a just and equitable world where myriad worldviews can cohabit. Despite this expanding representativeness in society, inequalities prevail within ethnically diverse populations, such as among Indigenous Peoples, and this is especially true when it comes to accessibility to healthcare and medical education (Jones et al., 2019; Sloof et al., 2021). These discrepancies stem from colonization and its legacy (Truth, and Reconciliation Commission of Canada, 2015; Jones et al., 2019) and are still prevalent in certain health professions, notably such as in medicine (Castillo-Page, 2008). According to a brief 
overview regarding the current status of racial and ethnic minorities among medical school applicants provided by the Association of American Medical Colleges, American Indians and Alaska Natives represent the lowest percentage of U.S. medical school applicants and represent $0.4 \%$ compared with all other ethnic groups (Castillo-Page, 2008). This situation is similar in Canada where Indigenous students are underrepresented in medical schools, despite an urgent need to address inequalities regarding access to healthcare in rural and Indigenous communities (Author Anonymous, 2008).

As per the Association of American Medical Colleges (Castillo-Page, 2008), training doctors, scientists, or physicians with ethnically diverse backgrounds can help to overcome health disparities and access to healthcare, as well as to broaden the medical culture (Reeves et al., 2009). This implies that Indigenous Peoples should be represented in medical education as "an essential step in eliminating health disparities" (5, p.11). Consequently, examining the multiple barriers to medical education from the perspective of Indigenous students' motivation to pursue medical studies becomes an imperative next step.

In this paper, we draw on the lived experiences of Indigenous female medical students and apply the Self-Determination Theory (SDT) to understand the different forms of motivations that play a role in Indigenous students' pursuit of a medical career. We review the admission-specific challenges as perceived by Indigenous students, as well as the strategies applied to overcome the latter for medical school enrollment. Understanding and being aware of such motivations could inform practices aiming at fostering student success and retention in medical education, which in turn could indirectly contribute to improving inequalities within the health professions. Furthermore, such insights could also be relevant for other practitioners, educators, and researchers in the medical community who contribute to the instauration of institutional policies.

According to the Self-Determination theory, individuals' behaviors are motivated by three fundamental needs: autonomy, competence, and relatedness. Additionally, people's motivation may differ in terms of their degree of selfdetermination and with respect to the varying degrees of relative autonomy leading to two forms of motivations: an autonomous and a controlled form (Litalien et al., 2017). Autonomous motivation describes behaviors and decisions made for reasons that are regulated by choice and perceived as voluntary (Deci et al., 1991), whereas controlled motivation refers to the engagement in behaviors with a "lower sense of volition" and is usually related to internal or external factors or pressures (Litalien et al., 2017). More specifically, on the self-determination continuum, the most autonomous form of motivation is present when one engages in an activity simply for the pleasure and satisfaction experienced with it. This type of motivation implies a complete internalization of the activity (e.g., studying) without the need for external regulation (e.g., encouragement from the teacher) to perform the activity. At the end of the continuum, we find the most controlled form of motivation, which describes behaviors related to obtaining rewards (e.g., receive funding) or avoiding punishment or constraints (e.g., escape from adversity) (Deci and Ryan, 1985). Among these different types of motivations, studies in educational contexts show that autonomous forms of motivations are associated with more positive educational outcomes (Guay et al., 2016), such as higher retention in college (Vallerand and Blssonnette, 1992), as well as increased academic performance (Pintrich and de Groot, 1990; Grolnick et al., 1991). Self-determination theory has often been used in multiple studies examining the principles of psychology as applied to education contexts (Reeve et al., 2002) and is also used as a reference to frame the current study and to better understand Indigenous students' motivations to pursue a career in medicine.

\section{Admission-specific Barriers and Strategies to Enter Medical School}

Admission to competitive university programs is generally a challenging process for all students. For example, applying to medical studies can sometimes lead to the perception of being in an "elite" profession, having access to a social circle that provides detailed information about admissions, and securing the financial resources to cover program costs or funds for moving away (Reeves et al., 2009). These challenges may be exacerbated when we focus on under-represented groups such as Indigenous Peoples who may, at first glance, be penalized due to their "educational backgrounds, race, experiences of discrimination, cultural backgrounds, and language barriers" (16, p. 1053).

Nevertheless, Indigenous students who do pursue a medical career report finding motivation from a mix of personal and pedagogical experiences, including health-related work experience, college science courses, the competitiveness or challenge of being accepted to medicine, being in touch with a physician who acted as a role model, and parental support (Castillo-Page, 2008). In the last decade, several measures and efforts have been deployed to promote accessibility to medical programs for Indigenous Peoples such as outreach activities aimed at inspiring children in elementary schools to consider a career in medicine (McHarg et al., 2007), as well as modifications in the admission criteria and designated seats for students coming from rural and Indigenous communities (Rourke et al., 2005; Sloof et al., 2021).

Although these strategies are a step in the right direction, there is still a need for more upstream interventions that are conducive to sustainable forms of motivation among potential Indigenous students who are considering applying to medical school (Castillo-Page, 2008; McKivett et al., 2019). The latter deserves special attention, especially knowing that Indigenous students' motivations play a significant role in their consideration of medicine as a future career prospect (Sloof et al., 2021). Of utmost importance, increasing the representation of Indigenous students in medical programs contributes to diminishing health inequalities as under-represented minority physicians often choose to return to their home communities to practice and are more inclined to help disadvantaged patients (Author Anonymous, 2008; Easterbrook et al., 1999; Garvey et al., 2009). 


\section{Method}

This study was part of a bigger project examining Indigenous students' pathways in medical school ${ }^{1}$. To answer our research question, we adopted a qualitative phenomenological approach with open-ended interviews (Creswell, 2007) to explore Indigenous students' subjective lived experiences. Phenomenology is relevant and compatible with Indigenous ways of living that involve sharing, inclusion, and aligns with the central elements commonly found in the oral traditions and personal interactions in Indigenous communities. Phenomenological research has traditionally relied on multiple types of interviews, including open-ended ones (Beven, 2014). This study was also conducted in collaboration with the coordinator of medical programs for Indigenous students and the director of the Indigenous health professions programs in the three Canadian universities where this study took place.

\section{Context and Recruitment}

The Faculties of Medicine in the participating universities reserve four places annually for qualified Indigenous students, and this number has recently been on the uprise. This strategy is a result of a formal negotiation and discussion between the faculties of medicine, the Council of Band Leaders, and the Government [names blinded for review]. This specialized Indigenous medical admission stream contains a pipeline outreach, with interview preparation sessions and a joint selection between medical schools and members of Indigenous communities.

Recruitment of participants was conducted with respect to the Indigenous medical cohort's appropriate needs and with the guidance of two collaborators: the coordinator of the medical programs for the Indigenous stream and the director of the Indigenous health professions program. Specifically, three participants were recruited through the coordinator of the medical programs for the Indigenous stream and one through the director of the Indigenous health professions program. The former verbally announced the possibility to partake in this study during one of the Indigenous students' monthly informal gatherings. The latter announced the possibility to participate in this research through one of the orientations and welcome sessions held at the beginning of each semester. Both collaborators described the research study, the nature of the participation, as well as the research objectives with potential participants. Those who were interested in participating either communicated with one of the collaborators, who in turn forwarded their contact information to the researcher via email or emailed the researcher directly whose contact information was communicated to all attendees at the gatherings and the orientation sessions.

\section{Participants}

Participants ( $n=4$ females) ranged from 25 to 35 years of age and were at different stages in their medical program. All four participants had previously been enrolled in other university programs before entering medicine and were self-identified as

\footnotetext{
${ }^{1}$ Author 1 (blinded for review).
}

Indigenous with their status authenticated by the coordinator of the medical programs. All participants had also been admitted to medical school through the Indigenous stream (Sloof et al., 2021). Although our total sample is composed of four participants only, three of four were selected specifically from the coordinator of the medical programs for the Indigenous stream who deemed these voices to be somewhat representative of the 40 currently active medical students admitted through the Indigenous stream.

Annie (pseudonym): In high school, Annie was involved in swimming competitions and played the piano. She described herself as an average-performing student who had a relatively small social circle of friends at school.

Sarah (pseudonym): Sarah had experience babysitting children and as a lifeguard. In high school, she was enrolled in an International Baccalaureate program and volunteered with elderly people as part of the community service component in her program.

Jessica (pseudonym): Before medical school, Jessica played and taught the piano. She also studied and received a degree in music. She described her educational journey as a positive one and considered herself privileged for having a comfortable family life.

Audrey (pseudonym): Because of past negative experiences associated with racism and perceived negative beliefs regarding the Indigenous culture, Audrey's family kept her background and cultural heritage a secret until much later in her life. Audrey described herself as solitary and a perfectionist who spent many hours in summers reading just like her mother who was a high school teacher and an avid and enthusiastic reader as well.

\section{Data Collection and Analysis}

Research Ethics Board approval was granted before data collection began. The first author conducted in-depth, openended interviews with the participants. At the beginning of the interview, the interviewer (the first author) provided a brief overview of the procedures and the content to be discussed. Upon agreement and understanding, informed consent forms were signed. All interviews lasted between 60 and $90 \mathrm{~min}$, were audio-recorded, transcribed verbatim, and securely stored for analysis. This study presents the first of three interviews focusing on past academic and personal experiences that may have been direct or indirect sources of motivations and indicative of participants' earlier interests in applying to medical school. Typical open-ended questions focused on specific topics related to past academic background, work experiences, family support, and the medical admissions process. Interviewees were very familiar with these questions and were at ease when providing answers.

A thematic analysis was carried out using the qualitative software NVivo version 12. In the first round of analysis, a first researcher (LB) independently coded all the transcripts in separate NVivo files while a second researcher (SR) coded only one transcript. Intercoder reliability and agreement were thus conducted on $25 \%$ of the data, which corresponded to one interview transcript. According to Lombard et al. (2003) achieving intercoder reliability on $10 \%$ of the data is adequate. The themes that emerged and their respective quotes were reviewed and compared. In cases of disagreement or missing 
themes between researchers' analyses, coding was discussed until consensus was reached. Themes and quotes that were deemed irrelevant to students' motivation to apply to medical school were dropped. In the second round of analysis, researchers independently sorted the first level of themes into bigger categories that reflected similar themes. Researchers then compared these categories, if disagreements arose, coding was discussed until consensus was reached. The first level of themes of the remaining three transcripts was then categorized into these bigger categories. Alternatively, if the researchers deemed it necessary, additional categories were created to sort remaining themes.

\section{FINDINGS}

Two main themes emerged from this study whose focus was to explore Indigenous students' motivation for pursuing medical studies. The first theme reflected the pedagogical experiences, including factors related to academic interests, that played a positive role in Indigenous students' motivations. The second theme reflected the personal experiences such as family support and future career prospects that contributed to Indigenous students' motivations to apply to medical school.

\section{Pedagogical Experiences}

Academic interests. The diversity in participants' academic interests and educational paths leading them to the field of medicine was an important contributing factor to Indigenous students' motivation. Annie explained that she was interested in sciences and math in high school and disliked the arts and social sciences. She was also not too warm about language arts because she experienced difficulties with her writing skills. Sarah, on the other hand, worked on a project about skin cancer while she was in college which sparked a marked interest in the field: “ . . the project itself was really fun and it taught me a lot about skin cancer and ... I've always had an interest in it and now I want to do an internship in dermatology".

As for Jessica, after beginning a career in teaching music at the high school level, she switched gears due to challenging working conditions (e.g., the necessity to work in three to four different schools to get a full-time position) and enrolled in a college-level biology course, something which she had been wanting to do for a long time. Jessica enjoyed this course which she qualified as being wonderful partly due to her excellent and passionate teacher: "It's just like something that I didn't know and that I still find fantastic today, you know, it's impressive when you understand a little bit how [biology] works" (Free translation). Furthermore, this leap into the sciences and, ultimately, the medical field was due to the encouragement Jessica received from her biology teacher whom she regarded as being passionate about the field: "Then the professor told me you should try it. He thought it was strange that I was applying in pharmacy".

Finally, Audrey who was also a certified English Second Language teacher had begun studies in a nursing program and, eventually, transferred to psychology in which she completed her undergraduate education. Audrey expressed her need to complete an undergraduate degree before applying into a medical field:

So basically all these things, it's sort of came to an end and I realized that I had to do something and the first thing I need to do is that I need to get my degree. Because if I don't have a degree ... then I have nothing. So, I decided in fall, I said that's it. I went to see an advisor at the university.

In sum, it seems that these Indigenous students pursued the medical field initially through other outlets that they discovered during their previous studies, and that their positive learning experiences reinforced their intentions to pursue medicine.

\section{Personal Experiences}

Family support and influence. All the participants indicated that their family members motivated them to pursue medicine by informing them about the Indigenous stream for admissions. Annie learned about the latter from her aunt, whereas Sarah and Jessica learned about it through one of their parents. Audrey's mother, on the other hand, suggested that she apply for nursing, not medicine because she could obtain a nursing degree in a matter of years and be able to work anywhere in the world, and if nursing was not enjoyable, she could then move on to medicine.

Family members also served as exemplary role models when it came to considering a career in medicine. For example, Sarah's mother worked in the health field, and Annie's grandfather was a doctor. As for Audrey, she developed an interest in the health field because medicine had always been a topic of conversation in her family:

My brother did it and I always had an interest. My mom was always interested in biology. She wanted to be a doctor. So, it was always sort of humming in the back and because I had all these jobs in human services with health and always had the interest, I thought, you know what, I should just go for this. If I apply and don't get in, I could always try next year.

All participants also emphasized the value their parents placed on education and the support they provided in their endeavors. Annie was always taught that school was a priority and was encouraged to take part in extracurricular activities without the pressure of performance. Her mother was very supportive and reminded her that "even though [she] did super bad sometimes [her mother would say] ... it's just like it's for fun anyways, ... you are not going to do this for the rest of your life so have fun, if you don't perform, it doesn't matter ... no pressure." Similarly, Sarah said that her parents always supported her in education and pushed her to study in the health sciences: "My parents always really encouraged me in this, and ... they were ... kind (Free Translation)."

Future career prospects. Decisions to apply to medical school were mostly driven by participants' vision of their prospects and what would be fulfilling for them in the long term. For example, Annie stated that her motivation for attending medical school was primarily because of job security and, secondly, because her "father and everyone was getting sick on [her] dad's side". Sarah also mentioned that she discovered a passion for helping 
Indigenous Peoples which provided meaning, purpose, and a sense of direction to her life and for her future work in medicine.

Both Sarah and Audrey also reported extending the satisfaction they felt from their prior work experiences to the medical field. Sarah's work and volunteering experiences in retail and hospital settings, as well as her experiences as a babysitter, confirmed that she enjoyed working with children and, especially, that she wanted to continue working in a social environment in which she could constantly contribute and help others.

\section{DISCUSSION}

This study aimed at describing female Indigenous students' motivations for pursuing a career in medicine. Through participants' narratives, it seems that the past academic environment acts as a significant source of motivation when thinking about applying to medicine. Other forms of motivation seemed to have developed through more of an internal pressure wherein the avoidance of a negative experience (e.g., having to study in the arts or languages) eliminated the possibility of pursuing studies in a subject that one dislikes or is not interested in. The latter can be interpreted as a form of controlled motivation because it is regulated by external contingencies (i.e., avoidance of punishment or an undesired outcome) as opposed to an autonomous form of motivation (i.e., intrinsic) which represents interests that are derived from within the individual and without being contingent to other external factors.

With regards to personal experiences, family support played an influential role in contributing to Indigenous students' decision to pursue a career in medicine. The option of applying into the field through an Indigenous stream was often communicated by family members and served yet as another source of motivation. It was perceived by students as a chance to be admitted, despite the lack of belief and selfconfidence of being accepted through the mainstream admission process. Because family members served as exemplary role models and transmitted the value they placed on education to their children, they contributed to Indigenous students' willingness to apply to medicine. Retrospectively, students' willingness to apply to medicine was also reflected in their sense of wanting to contribute to the health of family members. This process indirectly motivated Indigenous students by creating somewhat of an internal pressure to pursue medical studies. Aside from family support, it seems that admission into medicine was also important for a valued outcome: finding meaning, relevance, purpose, and a sense of direction for one's life and future career as a doctor.

Results of the present study are encouraging in the sense that they demonstrate participants who were well supported when applying into medicine and are now thriving in school. Furthermore, being motivated autonomously is hopeful because it is a positive indicator of long-term, optimal educational outcomes. These results are also meaningful in showing us that different types of motivations can work in the students' favor when debating to apply for medical school, but they may not be sufficient for the tipping point. In addition to their motivations, also learning about the Indigenous stream for admissions into medicine is what sealed students' confidence to pursue with their application.

\section{Limitations}

Limitations of the present study included the sample size. Results stemming from only four participants cannot be generalized and representative of Indigenous People's lived experience; however, participants' language was not modified during data coding, as well as in the communication of the results to preserve as much as possible the authenticity of their lived experiences.

In addition, the retrospective aspect of the data collection could have influenced results. Data regarding participants' motivations to pursue a medical career were collected during their studies. They had already been accepted and had already started their journey. Thus, instead of capturing motivations during the pre-admission period, data were collected retrospectively, which may have biased the results (e.g., participants may be reconstructing their memories rather than describing what had happened).

Another concern is the sampling method because we relied on Indigenous staff for recruitment. The sample might have been biased toward students who had already been supported and motivated to apply to medical school by their university, which in turn could have influenced their motivations to apply to medical school. On the other hand, by relying on Indigenous staff for recruitment we respected a more collaborative research partnership and provided them with the flexibility to choose individuals whose voices would be more representative.

Finally, analyses were conducted by non-Indigenous authors, which may be perceived as contributing to the perpetuation of a colonial legacy. Although we are not Indigenous researchers, nor do we claim to be using Indigenous research methodologies, we have complemented the interpretation of our results by including member-checking with all participants and holding regular meetings with the coordinator and director of the Indigenous stream in medical programs regarding the interpretation of the research results.

\section{Future Research and Conclusion}

There are many examples of Indigenous academic success, however, little is known about how to identify, measure, and emulate these successes more broadly. This may be partly due to limited concerted research being founded upon the voices and agency of Indigenous Peoples that has not yielded to the full potential of translating evidence-based data to meaningful policy and impacts. In this paper, we described the lived experiences of Indigenous female students' motivation to apply to a medical program. This research prioritized the voices and agency of Indigenous students and used a research framework founded upon the Self-Determination Theory that delineates autonomous versus more controlled forms of motivations.

Considering the current findings, a possible avenue for future research could be to study strategies on how to foster autonomous motivation in potential or first-year medical students. The latter should undoubtedly include Indigenous parents who have 
through these narratives proven their constant presence and belief in their children by providing an optimal environment for flourishment. Furthermore, researching ways on how to foster the development of autonomous motivation among new medical students could lead to insights on how to increase retention which, in turn, leads to other positive outcomes at the social level, such as addressing the underrepresentativeness of Indigenous populations in healthcare professions.

Finally, in terms of practical implications, more targeted efforts seem to be needed to promote the visibility of the Indigenous admission stream. There has been notable progress regarding the range of implemented strategies for a culturally safe admissions process for Indigenous student applicants with their growing representation across medical school years (Young et al., 2017). While themes related to the specialized admission stream are not entirely novel, the explicit linking of the latter to potential applicants' motivations that include a range of diverse sources is a novel contribution and something to consider for future collaborations and research partnerships that aim to evaluate the short and long-term impact of pedagogical experiences on Indigenous medical students' academic motivation.

\section{DATA AVAILABILITY STATEMENT}

The datasets presented in this article are not readily available because Ethics approval did not include sharing datasets of vulnerable populations' interview transcripts. Requests to access the datasets should be directed to tanya.chichekian@ usherbrooke.ca

\section{REFERENCES}

Author Anonymous (2008). Conseil canadien sur l'apprentissage. SousReprésentation Des Communautés Autochtones et Rurales Dans Les Écoles de Médecine Du Canada. Montreal: Canadian council on learning. http:// bibliotheque.copian.ca/ajout/10608 http://www.bdaa.ca/biblio/recherche/cca/ aboriginal_rural_fr/aboriginal_rural_fr.pdf

Castillo-Page, L. (2008). Diversity in Medical Education: Facts \& Figures 2008. Association of American Medical Colleges, 146.

Creswell, J. W. (2007). Qualitative Inquiry and Research Design: Choosing Among Five Approaches. 2nd ed. Thousand Oaks: Sage Publications.

Deci, E. L., and Ryan, R. M. (1985). Intrinsic Motivation and Self-Determination in Human Behavior. Plenum Press.

Deci, E. L., Vallerand, R. J., Pelletier, L. G., and Ryan, R. M. (1991). Motivation and Education: The Self-Determination Perspective. Educ. Psychol. 26 (3-4), 325-346. doi:10.1080/00461520.1991.9653137

Easterbrook, M., Godwin, M., Wilson, R., Hodgetts, G., Brown, G., Pong, R., et al. (1999). Rural Background and Clinical Rural Rotations during Medical Training: Effect on Practice Location. CMAJ 160 (8), 1159-1163.

Garvey, G., Rolfe, I. E., Pearson, S. A., and Treloar, C. (2009). Indigenous Australian Medical Students' Perceptions of Their Medical School Training. Med. Educ. 43 (11), 1047-1055. doi:10.1111/j.1365-2923.2009.03519.x

Grolnick, W. S., Ryan, R. M., and Deci, E. L. (1991). Inner Resources for School Achievement: Motivational Mediators of Children's Perceptions of Their Parents. J. Educ. Psychol. 83 (4), 508-517. doi:10.1037/00220663.83.4.508

Grzymala-Kazlowska, A., and Phillimore, J. (2018). Introduction: Rethinking Integration. New Perspectives on Adaptation and Settlement in the Era of

\section{ETHICS STATEMENT}

The studies involving human participants were reviewed and approved by Université du Québec À Montréal. The patients/ participants provided their written informed consent to participate in this study.

\section{AUTHOR CONTRIBUTIONS}

All authors listed have made a substantial, direct, and intellectual contribution to the work and approved it for publication.

\section{FUNDING}

This research was facilitated by a Social Sciences and Humanities Research Council-Insight Development Grant (\#430-201601160) allocated to the first author.

\section{ACKNOWLEDGMENTS}

We wish to acknowledge the contribution of the Indigenous students throughout the interpretation of our data analyses. Writing this manuscript would not have been possible without the participants' contribution of their precious time and the sharing of their perspectives regarding their medical education journeys. We also want to thank Catherine Maheux, Karolane Beaulieu and Gabriel Lemay-Lapointe for helping with the data analysis and providing constructive feedback.

Super-diversity. J. Ethnic Migration Stud. 44 (2), 179-196. doi:10.1080/ 1369183X.2017.1341706

Guay, F., Lessard, V., and Dubois, P. (2016). "How Can We Create Better Learning Contexts for Children? Promoting Students' Autonomous Motivation as a Way to Foster Enhanced Educational Outcomes," in Building Autonomous Learners: Perspectives from Research and Practice Using Self-Determination Theory. Editors WC. Liu, J. C. K. Wang, and R. M. Ryan (Springer), 83-106. doi:10.1007/978-981287-630-0_5

Jones, R., Crowshoe, L., Reid, P., Calam, B., Curtis, E., Green, M., et al. (2019). Educating for Indigenous Health Equity: An International Consensus Statement. Acad. Med. 94 (4), 512-519. doi:10.1097/ ACM.0000000000002476

Litalien, D., Morin, A. J. S., Gagné, M., Vallerand, R. J., Losier, G. F., and Ryan, R. M. (2017). Evidence of a Continuum Structure of Academic Self-Determination: A TwoStudy Test Using a Bifactor-ESEM Representation of Academic Motivation. Contemp. Educ. Psychol. 51, 67-82. doi:10.1016/j.cedpsych.2017.06.010

Lombard, M., Snyder-Ducc, J., and Bracken, C. C. (2003). Practical Resources for Assessing and Reporting Intercoder Reliability in Content Analysis Research Projects. Available at: http://www.temple.edu/mmc/reliability.

McHarg, J., Mattick, K., and Knight, L. V. (2007). Why People Apply to Medical School: Implications for Widening Participation Activities. Med. Educ. 41 (8), 815-821. doi:10.1111/j.1365-2923.2007.02798.x

McKivett, A., Paul, D., and Hudson, N. (2019). Healing Conversations: Developing a Practical Framework for Clinical Communication between Aboriginal Communities and Healthcare Practitioners. J. Immigr Minor. Health 21 (3), 596-605. doi:10.1007/s10903-018-0793-7

Pintrich, P. R., and de Groot, E. V. (1990). Motivational and Self-Regulated Learning Components of Classroom Academic Performance. J. Educ. Psychol. 82 (1), 33-40. doi:10.1037/0022-0663.82.1.33 
Reeve, J. (2002). "Self-Determination Theory Applied to Educational Settings,"in. Handbook of Self-Determination Research. Editors E. L. Deci and R. M. Ryan (Rochester: University Rochester Press), Vol. 2, 83-204.

Reeves, S., Fox, A., and Hodges, B. D. (2009). The Competency Movement in the Health Professions: Ensuring Consistent Standards or Reproducing Conventional Domains of Practice? Adv. Health Sci. Educ. Theor. Pract 14 (4), 451-453. doi:10.1007/s10459-009-9166-2

Rourke, J., Dewar, D., Harris, K., Hutten-Czapski, P., Johnston, M., Klassen, D., et al. (2005). Strategies to Increase the Enrollment of Students of Rural Origin in Medical School: Recommendations from the Society of Rural Physicians of Canada. CMAJ 172 (1), 62-65. doi:10.1503/ cmaj.1040879

Sloof, N., Blue, T., Hansen, B., Amer Ali, L., and Kim, G. (2021). Building Pathways to Healthcare Education with Indigenous Youth: An Integrative Approach. Med. Educ. 55 (5), 653. doi:10.1111/medu.14510

Truth, and Reconciliation Commission of Canada (2015). Honoring the Truth, Reconciling for the Future. Montreal: Truth and Reconciliation Commission of Canada, 319-338. https://www.mqup.ca/honorer-la-v-rit--r-concilierpour-l-avenir-products-9780773546707.php.

Vallerand, R. J., and Blssonnette, R. (1992). Intrinsic, Extrinsic, and Amotivational Styles as Predictors of Behavior: A Prospective Study. J. Personal. 60 (3), 599-620. doi:10.1111/j.1467-6494.1992.tb00922.x
Young, M. E., Thomas, A., Varpio, L., Razack, S. I., Hanson, M. D., Slade, S., et al. (2017). Facilitating Admissions of Diverse Students: A six-point, EvidenceInformed Framework for Pipeline and Program Development. Perspect. Med. Educ. 6 (2), 82-90. doi:10.1007/s40037-017-0341-5

Conflict of Interest: The authors declare that the research was conducted in the absence of any commercial or financial relationships that could be construed as a potential conflict of interest.

Publisher's Note: All claims expressed in this article are solely those of the authors and do not necessarily represent those of their affiliated organizations, or those of the publisher, the editors and the reviewers. Any product that may be evaluated in this article, or claim that may be made by its manufacturer, is not guaranteed or endorsed by the publisher.

Copyright (C) 2022 Chichekian, Bragoli-Barzan and Rahimi. This is an open-access article distributed under the terms of the Creative Commons Attribution License (CC BY). The use, distribution or reproduction in other forums is permitted, provided the original author(s) and the copyright owner(s) are credited and that the original publication in this journal is cited, in accordance with accepted academic practice. No use, distribution or reproduction is permitted which does not comply with these terms. 